\title{
Safeguards in Blood Supply: A National and European Challenge
}

\author{
Beat M. Frey ${ }^{a}$ Peter Schlenke ${ }^{b}$ \\ a Blood Transfusion Service SRC, Schlieren-Zürich, Switzerland \\ ${ }^{\mathrm{b}}$ Institute of Transfusion Medicine and Transplantation Immunology, University Hospital Münster, Germany
}

Today, the safe and adequate supply with blood products is taken for granted. However, the nationwide allocation of such blood products is not based on a large-scale production in pharmaceutical plants, but on the altruistic help of millions of volunteer and healthy blood donors. Historically, seminal discoveries such as the $\mathrm{ABO} / \mathrm{RhD}$ blood groups, the transfusion rules derived from them, as well as developments in the field of medical technology, which allow to manufacture of storable and standardized blood products have contributed significantly to the success of transfusion medicine. Many medical achievements would be unimaginable without the efficient, safe and professionally organized blood supply. This progress has been discontinued in the 1990's by the emergence of acquired immunodeficiency syndrome (AIDS) of which the infectious agent (human immunodeficiency virus; HIV) has been spread also by blood products and plasma derivates. Great efforts and the deployment of big resources have been necessary to restore the faith of people in the treatment with blood products (hemotherapy). The current issue of Transfusion MediCINE AND Hemotherapy deals with safeguards in blood supply on a national and European level. The first part gives an overview of the efforts made to guarantee blood supply and blood safety during the last 20 years. The second part outlines future challenges that have to be overcome to preserve the currently safe blood supply also for future generations.

Seitz et al. [1] summarize the rules and authorities implemented in German-speaking Europe, by which the inherent perils of recovery, manufacture and use of blood products were reduced to infinitesimal residual risk. Above all, the interdisciplinary efforts of the recent years have restored the confidence of the public in transfusion medicine. Similarly, successful efforts in this matter in other regions with highly developed health care services allow now to exchange blood products across national boundaries despite extraordinary requirements for quality and safety.
Roth [2] describes how modern nucleic acid-based test procedures for infectious diseases, i.e. NAT screening, call into question earlier safety procedures in the manufacture of plasma (quarantine) for transfusion. Therefore, with respect to the scarce resources, the principle of substitutive innovation should be applied more frequently in the field of transfusion medicine.

Offergeld et al. [3] describe epidemiological insights derived from hemovigilance data, and how these newly created surveillance and reporting procedures for adverse effects of blood products develop into early-warning systems for new menaces to the blood supply. The authors recognize the generalizable phenomenon of 'HIV sorting' as an only scarcely investigated phenomenon of modern donor screening suggesting adjustments of the current donor selection criteria.

The article by Katalinic et al. [4] focuses on the health economical foresight. As a result of the demographic change in Western societies and of the progress in curative medicine, an ever growing part of the health budget needs to be spent for the treatment of age- und lifestyle-related morbidity. At the same time, the dwindling birth rate narrows the basis of gainfully employed persons and thus quickens the shrinkage of the resources available for health and welfare.

Ehling et al. [5] present detailed forecasts on demographic development and its consequences for blood supply until 2060. These prognoses are based on the 12th coordinated population projection for Germany, given by the Federal Statistical Office. The authors list the low birth rate, the increasing life expectancy and the only badly foreseeable migration activities as the main reasons for future shortfalls in blood supply. The recruitment of new groups of the society to become blood donor will develop into a great challenge for representatives of transfusion medicine within the next years.

Greinacher et al. [6] describe some kind of a worst-case scenario for local blood supply: Not only the natural change

\section{KARGER}

Fax +497614520714

Information@Karger.de

www.karger.com (c) 2010 S. Karger GmbH, Freiburg

Accessible online at:

www.karger.com/tmh
Dr. Beat M. Frey

Blood Transfusion Service SRC

Rütistrasse 19, 8952 Schlieren, Switzerland

bm.frey@zhbsd.ch 
of the demographic population structure but also variably pronounced political and socioeconomic changes in the respective areas will contribute to the local supply shortage in blood products.

Goette et al. [7] present theoretical and practical aspects of motivation research in respect to blood donation behaviour of the population. Recent data do not allow for definite conclusions regarding the effectiveness of extrinsic triggers for blood donation. Depending on the context of their use, these triggers are permissive or counterproductive with respect to blood donation behavior. Moreover, the authors show that survey-based motivation research does not contribute significantly to the understanding of prosocial behavior. Therefore, they call for prospectively conducted field studies that will give deeper insights into these interrelationships. The ex- pected increase in demand for blood products in the future, together with the dwindling donor population will result in a prominent role of these type of research activities in the field of transfusion medicine.

The authors of the editorial hope that the presented issue of Transfusion Medicine and Hemotherapy will stimulate the discussion at the XXXIst international congress of the International Society of Blood Transfusion (ISBT) in joint cooperation with the 43rd congress of the Deutsche Gesellschaft für Transfusionsmedizin und Immunhämatologie (DGTI) in June 2010 and will give a sustained starting signal to intensify commitment and research in the field of public health, in order to maintain a blood donor population that is big enough to suffice future demands for blood supply.

\section{References}

1 Seitz R, Heiden M: Quality and safety in blood supply. Transfus Med Hemother 2010;37(3):112-117.

2 Roth WK: Quarantine plasma: quo vadis? Transfus Med Hemother 2010;37(3):118-122.

3 Offergeld R, Hamouda O, Burger R: Epidemiological data - an important part of the hemovigilance system. Transfus Med Hemother 2010;37(3): $125-130$.
4 Katalinic A, Peters E, Beske F, Pritzkuleit R: Projection of morbidity 2030 and 2050: impact for the national health system and blood supply. Transfus Med Hemother 2010;37(3):155-159.

5 Ehling M, Pötzsch O: Demographic changes in Germany up to 2060 - consequences for blood donation. Transfus Med Hemother 2010;37(3): 131-139.
6 Greinacher A, Fendrich K, Hoffmann W: Demographic changes: the impact for safe blood supply. Transfus Med Hemother 2010;37(3):141-148.

7 Goette L, Stutzer A, Frey BM: Prosocial motivation and blood donations: a survey of the empirical literature. Transfus Med Hemother 2010;37(3): 149-154. 